\title{
PRÁTICAS PARENTAIS: REFLEXÕES SOBRE RELATOS DE FAMILIARES DE USUÁRIOS DE CRACK
}

\author{
Maria das Graças Rojas Soto \\ Universidade Federal do Mato Grosso do Sul \\ Fundação Oswaldo Cruz \\ Verônica Fabíola Rozisca \\ Universidade Federal do Mato Grosso do Sul \\ Rivaldo Venâncio da Cunha \\ Fundação Oswaldo Cruz \\ Universidade Federal do Mato Grosso do Sul
}

\begin{abstract}
Resumo
As características na dinâmica familiar podem influenciar no consumo de drogas. O estudo objetivou compreender práticas parentais em famílias de usuários de crack. Este é um estudo qualitativo, realizado por meio de entrevistas individuais com 20 familiares de usuários de crack cadastrados em um serviço público de saúde mental de um município do Mato Grosso do Sul. A coleta de dados ocorreu entre novembrodezembro/2014 e os dados foram analisados pela técnica de análise de conteúdo. Na maioria das famílias, as regras são estabelecidas pela mãe e seu descumprimento acarreta punição física. Os filhos são descritos como muito obedientes, porém as ordens ditadas são vagas ou ambíguas, o que resulta na ausência de limites claros a serem seguidos. Conclui-se que tal dinâmica dificulta o desenvolvimento da regulação emocional, tolerância à contrariedade, resistência à frustração e habilidades de negociação e solução de problemas, que podem influenciar no consumo do crack.

Palavras-chave: crack; relações familiares; estilo parental.
\end{abstract}

\section{PARENTING PRACTICES: REFLECTIONS ON FAMILY MEMBERS OF CRACK COCAINE USERS REPORTS}

\begin{abstract}
Features of family dynamics may influence drug consumption. This study aimed to comprehend parenting practices in families of crack cocaine users. This is a qualitative research, carried out through individual interviews applied to 20 family members of crack cocaine addicts enrolled at a mental health public service in city of Mato Grosso do Sul/Brazil. Data were collected from November to December of 2014 and analyzed by the content analysis technique. In most families, rules are established by mother and their break leads to physical punishment. Children are described as obedient, but the dictated orders are vague or ambiguous, resulting in the absence of clear limits to be respected. We conclude that such dynamics hinder the development of emotion regulation, tolerance to opposition, resistance to frustration, and skills of negotiation and problem solving, what may influence the consumption of crack.

Keywords: crack; family relations; parenting style.
\end{abstract}




\title{
PRÁCTICAS PARENTALES: REFLEXIONES SOBRE INFORMES DE FAMILIARES DE USUARIOS DE CRACK
}

\begin{abstract}
Resumen
Características en la dinámica familiar pueden influir en el consumo de drogas. El estudio tuvo como objetivo comprender prácticas parentales en familias de usuarios de crack. Este es un estudio cualitativo, realizado mediante entrevistas individuales con 20 familiares de usuarios de crack registrados en un servicio público de salud mental de un municipio de Mato Grosso do Sul. Los datos fueron recolectados entre noviembre-diciembre/2014, y analizados según la técnica de análisis de contenido. En gran parte de las familias, la madre determina las reglas y no cumplirlas causa castigo físico. A los hijos se los describe como muy obedientes, pero las órdenes son vagas o ambiguas, lo que resulta en ausencia de límites claros a los cuales atenerse. Se concluye que tal dinámica dificulta el desarrollo de regulación emocional, tolerancia a contrariedad, resistencia a frustración y capacidad para negociar y solucionar problemas, y puede influir en el consumo de crack.
\end{abstract}

Palabras clave: crack; relaciones familiares; estilo parental.

\section{INTRODUÇÃO}

O consumo do crack no Brasil foi registrado por primeira vez na década de 90 e, desde então, vem aumentando nas capitais e no interior. Em 2012, o país foi apontado como o maior mercado mundial de consumo de crack (Laranjeira, Madruga, Pinsky, Mitsushiro, \& Caetano, 2012) e o último levantamento nacional revelou 370 mil usuários de crack nas capitais brasileiras, número correspondente a $35 \%$ dos indivíduos que consomem drogas ilícitas no país (Fundação Oswaldo Cruz [FIOCRUZ] \& Instituto de Comunicação e Informação Científica e Tecnológica em Saúde [ICICT], 2014).

Apesar de o crack figurar em $10^{\circ}$ lugar entre as drogas mais consumidas no Brasil (com exceção do álcool e do tabaco), os prejuízos que este acarreta convertem-no em um problema de saúde pública e de relevância acadêmica (Laranjeira et al., 2012). Dentre as consequências do consumo de crack, são relatados danos diretos, como problemas pulmonares, cardiovasculares, necrose muscular, prejuízos neurocognitivos, comprometimento do sistema imunológico, e os indiretos, como infecção por HIV e outras doenças sexualmente transmissíveis. Além destes, não são poucos os prejuízos sociais resultantes, como isolamento, problemas no convívio familiar, dificuldades ocupacionais, comprometimento do lazer e da gestão financeira (Sayago, Lucena-Santos, Ribeiro, Yates, \& Oliveira, 2013) e nível de qualidade de vida inferior ao de indivíduos que não fazem uso de substâncias psicoativas (Moreira et al., 2013; Moura, Benzano, Pechansky, \& Kessler, 2014).

Segundo FIOCRUZ e ICICT (2014), embora atinja todas as camadas sociais, gênero e idade, o perfil dos consumidores de crack é de adultos jovens (média 30 anos), predominantemente do sexo masculino, maioria de cor negra ou parda, de baixa escolaridade (ensino fundamental), maioria solteira, em situação de rua e poliusuários (com sobreposição de álcool e tabaco). Dentre os motivos que levaram ao consumo de crack ou similares, cerca de $1 / 3$ dos 
usuários afirmam tê-lo iniciado devido a problemas familiares e afins, corroborando os dados de estudos norte-americanos com população de usuários de drogas em geral.

A questão da influência familiar no consumo de drogas tem sido abordada sob diversos paradigmas, tão complexa ela se mostra. Em uma concepção sistêmica a família é compreendida como um sistema social em que os seus elementos se encontram ligados por uma teia relacional e emocional, com um caráter dinâmico e em constante mudança, influenciando-se mutuamente em um processo de retroalimentação destes entre si e entre estes e o meio. 0 fenômeno é visto como um todo, com uma causalidade circular, sem começo e sem fim. Desta forma, o papel das famílias no processo de recuperação do paciente, assim como de adoecimento, é considerado muito importante, uma vez que a mudança familiar favorece a individual e vice-versa (Costa, 2010). É com base nesta concepção que, cada vez mais, são elas alvo de intervenção das equipes de saúde da atenção primária, que as veem como aliadas fundamentais e indispensáveis no tratamento do paciente usuário de drogas, buscando o cuidado integral do grupo familiar, oportunizando mudanças no grupo e no paciente (Medeiros, Maciel, Souza, Tenório-Souza, \& Dias, 2013; Paula, Jorge, Vasconcelos, \& Albuquerque, 2014; Paula, Jorge, Albuquerque, \& Queiroz, 2014; Claro et al., 2014). Este estudo apresenta autores que utilizam terminologia de abordagens clássicas, como a epidemiologia (fator de risco/ fator de proteção), somados a outros com um enfoque mais globalizado, buscando, por meio da complementaridade, compreender o fenômeno de forma mais integrada.

Pesquisas sobre o consumo de álcool e outras drogas no Brasil e no mundo revelam que o início da experimentação e consumo abusivo das drogas se dá na passagem da infância para a adolescência (Marquez \& Cruz, 2000; Silva et al., 2014) e que as primeiras relações que o indivíduo estabelece na família guardam relação com este abuso.

Segundo Schenker e Minayo (2005) os fatores de risco para o consumo da droga englobam aspectos culturais, interpessoais, psicológicos e biológicos, como disponibilidade das substâncias, privações econômicas, consumo de drogas pela família, conflitos familiares graves, baixo aproveitamento escolar, início precoce do uso, suscetibilidade herdada e vulnerabilidade ao efeito das drogas.

Estudos apontam a existência de vínculos saudáveis - com delimitação das responsabilidades, limites claros, comunicação adequada, apoio e afeto familiar - como um fator protetor quanto ao consumo de drogas. Por meio da construção de tais vínculos, a família comunica normas sociais salutares para seus membros (Schenker \& Minayo, 2003; Schenker \& Minayo, 2005; Paz \& Colossi, 2013). Famílias com distanciamento afetivo, dificuldade de comunicação e confusão de papéis de pais e filhos, adotam modelos de comportamentos que podem transmitir normas desviantes aos filhos, favorecendo o consumo de drogas e a 
permanência da dependência (Schenker \& Minayo, 2003; Schenker \& Minayo 2005; Paz \& Colossi, 2013). Assim, considerando a influência da família como fator de proteção ou de risco ao consumo de drogas, esta pode variar conforme a dinâmica estabelecida no grupo (Schenker \& Minayo, 2005; Paz \& Colossi, 2013; Silva et al., 2014, Horta, Vieira et al., 2014, Longmann-Mills et al., 2015).

Por outro lado, em uma visão sistêmica, considerando a causalidade circular ou reversa, pode se observar que, se o sofrimento causado pelos conflitos familiares favorece o consumo de crack, por sua vez, os problemas com o crack abalam profundamente a família, aumentam a disfunção no grupo e contribuem para o adoecimento deste, ambos se influenciando, portanto, de forma recíproca (Medeiros et al., 2013; Horta, Vieira et al., 2014, Claro et al., 2014).

Como primeiro núcleo social da criança, a figura dos pais e as práticas parentais adotadas têm grande influência no processo de construção das habilidades sociais do indivíduo. Estas envolvem comportamentos como assertividade, solução de problemas e empatia - aptidões fundamentais para o convívio entre as pessoas (Lohr, 2001). O desenvolvimento das tais habilidades está vinculado intensamente ao ambiente familiar, às vivências e às práticas sociais (Lubi, 2003).

Considerando os estilos parentais e sua influência sobre o consumo de drogas, foi realizado um estudo abordando a maneira como os pais lidam com questões de disciplina, hierarquia e apoio emocional na relação com os filhos (Benchaya, Bisch, Moreira, Ferigolo, \& Barros, 2011). A pesquisa revelou maior associação de abuso de drogas por parte dos filhos com pais de estilos autoritário e permissivo. Os autores apontam a influência positiva do estilo autoritativo, relacionando-o ao desenvolvimento de competência social, assertividade, autoestima e independência. O estilo parental se refere às atitudes dos pais na interação com os filhos em situações diversas, que podem apresentar afetividade, responsividade e autoridade. Considerando as formas de controle, este pode ser classificado em: autoritário (com rigidez e autocracia, altos níveis de controle e baixa responsividade), autoritativo (com autoridade englobando cordialidade e vigilância, em que as condutas são monitoradas corrigindo atitudes negativas e gratificando as positivas) e permissivo (com poucas demandas de controle e responsividade, pouca afetividade e exigência) (Schenker \& Minayo, 2003).

É comum encontrar nas famílias com dependentes químicos limites geracionais frágeis e conflitos no exercício dos papéis familiares. Nestas famílias, não estão bem delimitados os papéis de pais e filhos, de adultos com capacidade de estabelecer regras e crianças com consciência da existência destas; por esta razão, a disciplina fica enfraquecida ou inexistente (Moreira, 2004). Schenker e Minayo (2003) apontam nas famílias de dependentes químicos a existência de 
dificuldades no estabelecimento de limites e a ambiguidade das regras estipuladas.

Seleghim e Oliveira (2013) descrevem características no ambiente familiar, consideradas desfavoráveis, que atuam como elemento facilitador ao consumo de crack e outras drogas: ausência da figura materna ou paterna, deficiência nos vínculos entre os membros familiares que resulta em ausência de comportamentos de afeto, respeito e diálogo, regras familiares extremamente rígidas ou muito permissivas, cultura familiar implícita do consumo de álcool e outras drogas, agressão física, verbal e/ou psicológica, desinformação e desconhecimento sobre consumo de crack e outras drogas. Dentre estes aspectos, grande parte se refere a papéis geracionais, disciplina e estilos parentais, o que denota a relevância em conhecer como funcionam estes fatores nas relações intrafamiliares.

O objetivo deste estudo foi compreender as práticas parentais em relação a autoridade, regras e atitudes geradas pelo descumprimento destas em famílias de usuários de crack, tendo estes aspectos descritos pelo próprio grupo familiar.

\section{MÉTODO}

O presente artigo é parte de um estudo mais amplo denominado "Papel da dinâmica familiar no consumo do crack: aspectos socioculturais, demográficos e psicossociais" que teve como objetivo compreender o papel da dinâmica familiar no consumo do crack. A pesquisa foi aprovada pelo Comitê de Ética em Pesquisa envolvendo Seres Humanos, da Universidade Federal do Mato Grosso do Sul (protocolo no 867.334 - 10/11/2014). A participação dos indivíduos foi voluntária e se deu após a assinatura do Termo de Consentimento Livre e Esclarecido (TCLE). O estudo utilizou uma abordagem metodológica qualitativa, exploratória e foi realizado em uma cidade de fronteira do estado de Mato Grosso do Sul, na divisa com o Paraguai.

\section{Participantes}

Participaram da pesquisa 20 familiares de usuários de crack cadastrados em um serviço público de saúde mental, sendo um familiar por cada usuário. A amostra foi formada por conveniência e sua delimitação seguiu o critério de saturação das informações obtidas, que preconiza que a coleta seja encerrada quando os dados são considerados suficientes para atingir os objetivos da pesquisa e as falas começaram a se tornar recorrentes e repetitivas, sem acrescentar novas informações ao conteúdo já apreendido (Fontanella, Ricas, \& Turato, 2008).

Os critérios de inclusão foram: ser membro da família do usuário de crack que se encontra ou tenha passado por atendimento no serviço público de saúde mental desse município e idade superior a 18 anos. Os critérios de exclusão 
foram: estar no momento da entrevista sob o efeito de álcool ou outras drogas e aquelas com comprometimento cognitivo que resultasse em dificuldade para entender ou responder às perguntas.

\section{Instrumentos}

Para a coleta de dados foram utilizadas entrevistas individuais semiestruturadas, cujo roteiro abordava aspectos demográficos, culturais e psicossociais. Estavam assim constituídas: a primeira parte era referente à identificação sociodemográfica dos participantes; a segunda era composta por sete questões abertas que permitiam ao entrevistado discorrer livremente sobre o tema proposto, e contemplavam: aspectos positivos e negativos do grupo familiar, afinidades, preferências e descasos no grupo, conflitos e modo de resolução, regras e seu descumprimento, alegrias e afetividade, percepção do sentimento de ser amado, segundo a percepção da família a respeito de si mesma. O instrumento foi previamente testado para avaliar a sua adequação à proposta do estudo, verificando-se a validade semântica do mesmo. O tempo de duração de cada entrevista foi de 20 a 45 minutos, durante o período de novembro a dezembro de 2014.

\section{Procedimentos}

A equipe da instituição selecionou os prontuários dos pacientes usuários de crack, em número de 60 . Os pesquisadores gradativamente estabeleceram contato com as famílias destes pacientes, convidando um membro do grupo a participar do estudo. Foram considerados membros das famílias as pessoas vinculadas aos pacientes que reconheciam a si mesmas como integrantes do grupo familiar, não sendo exigido um determinado grau de parentesco para inclusão no estudo.

Os dados foram coletados no serviço público de saúde mental do município - instituição que concentra as famílias dos usuários de crack por incluílas no plano terapêutico do paciente - e no domicílio dos entrevistados. As entrevistas foram realizadas sem a presença dos pacientes. Após gravadas e transcritas na íntegra, estas foram submetidas a repetidas leituras, tabuladas, codificadas com a letra $\mathrm{P}$ (participante) seguida de um número, e categorizadas.

Os dados foram organizados e submetidos à análise de conteúdo temática proposta por Bardin (1977/2011), que utiliza um conjunto de técnicas de análise da comunicação dos sujeitos, aliados a procedimentos sistemáticos e objetivos de descrição do conteúdo desta, para, por meio da inferência e da interpretação, produzir sentidos e significados do discurso. O processo compreende três fases: pré-análise, exploração do material e tratamento dos resultados.

A análise de todo o material resultou na organização de nove categorias temáticas, sendo aqui abordada somente a categoria temática Regras e Limites: quem estabelece e forma de lidar com o descumprimento, gerada pelas 
respostas às perguntas "Como vocês definem regras na família? Quando descumprem, o que se faz?".

\section{RESULTADOS}

São características da amostra, constituída pelos familiares que compareceram para a entrevista: baixa escolaridade (14 no ensino fundamental - 70\%), classe econômica desfavorecida (17 com renda inferior a 01 salário mínimo - 85\%), residentes em zona urbana (20 - 100\%), em periferia (18 $90 \%$ ), provenientes de famílias recasadas (16 - 80\%), com número de uniões que variam de 02 a 05 . Os entrevistados foram em sua maioria do sexo feminino (15 mulheres e 05 homens), idade entre 31-60 anos (12-60\%), com a seguinte relação familiar: 06 mães, 02 pais, 04 irmãs, 07 cônjuges e 01 sobrinha.

Os pacientes usuários de crack, cujos familiares participaram do estudo, eram de ambos os sexos, sendo a maior parte homens ( 13 homens e 07 mulheres). A questão de gênero destes em relação à dinâmica familiar não foi avaliada neste estudo.

Resultante do processo de análise de conteúdo foi gerada a categoria temática descrita a seguir, que diz respeito aos limites e práticas parentais no grupo familiar, possibilitando a compreensão deste aspecto na dinâmica familiar.

Regras e Limites: quem estabelece e forma de lidar com o descumprimento.

Os relatos revelam ser a mãe a pessoa que define as regras na maior parte das vezes $(75 \%)$ nas famílias em que existe figura de autoridade:

Quem coloca mais as regras é a minha mãe. Depois que meu pai foi embora, eu era pequena tinha uns oito anos... a mãe (a respondente é irmã do usuário, referindo-se, portanto, à mãe de ambos) (P11)

...ela mandava em todos e nos castigava se não obedecíamos. Agora ela não tem mais regras sobre os filhos, tamo tudo grande, mas os filhos respeita, ela que manda (P14)

Há famílias em que todos ou ninguém estabelece regras e, na ausência de um modelo a seguir, nada é considerado inadequado e passível de correção:

...lá é tudo uma república, cada um no seu canto, ninguém manda em ninguém. Quando não faz eu pergunto: 'por que você não fez, coração? O que aconteceu?' E eles respondem: ' não aconteceu nada, eu não fiz de preguiça". E aí não dá nada, ninguém castiga ninguém. Desde pequeno é assim. Meus filhos nunca me desobedeceram (P6)

Observa-se dificuldade em alguns entrevistados em compreender o conceito de limites e regras, sendo estes muitas vezes relacionados à manutenção dos filhos, como o ato de suprir alimentos ou escolarização, como é possível observar no questionamento de uma entrevistada ao pesquisador: "Como assim? Quem manda na casa e fala o que pode ou não fazer? 
Mantimentos, você diz? Antes, quando era pequeno, era eu que matriculava, eu ia pra escola, tudo" (P18).

É frequente na fala dos entrevistados a ambivalência no discurso dos responsáveis ao ditar uma norma, a permissividade inerente a esta dubiedade e o relato de que os filhos foram crianças muito obedientes:

Eu falo pra eles 'você tem que fazer isso'... se não faz, eu falo de novo. $O$ menino pequeno de 11 anos que decide o que ele quer fazer e o que quer que eu faça. A M. (filha usuária, 16 anos) é bem obediente, esses dias atrás ela foi em casa, - daí eu cozinho pra ela qualquer hora porque tem que se alimentar bem - daí comeu, tomou banho e falou 'mãe, eu já vou pra rua de novo'. E eu falei pra ela: 'espera um pouco, filha, arruma e limpa a casa pra mãe, que eu tenho que sair, depois eu volto e te levo'. É duro pra uma mãe levar a filha pra droga, mas fazer o quê, melhor usar na rua que em casa. Daí eu voltei e ela tava me esperando, tinha limpado a casa, lavado a louça... Ela sempre obedece quando a gente pede (P7)

Eles (dois filhos) me obedeciam sempre, né. Mas tem uma pracinha na frente da minha casa, lá eles começaram a usar. Meus filhos nunca me desobedeceram, o problema é que eles saiam pra brincar aí. Mas eu não dou regras (P9).

Quando eles (dois filhos) eram pequenos eu ia muito na escola, brigava com o diretor... uma vez uma professora puxou a orelha do meu filho e eu processei ela; às vezes o $\mathrm{A}$. (filho usuário) tava com o problema com o professor que colocou ele pra fora da sala porque tava com birra dele, e eu discuti com o professor e arrumei outra escola, e aí já... passavam de ano (P18).

As crianças é tudo obediente, são todos educados. Tem um assim que dá mais um pouco de trabalho (filho usuário), sai assim, depois volta e às vezes quebra tudo. Mas é bonzinho também ele, bem bonzinho. Nunca mesmo eles me desobedecem (P16).

Sobre o descumprimento de regras, em $75 \%$ dos discursos este leva a uma punição física. As conversas explicativas/ admoestadoras, ameaças, gritos e xingamentos aparecem em $65 \%$ dos discursos. Os castigos, nos quais não há coação física, mas sim admoestação e privação de algum prazer ou privilégio, aparecem como atitude corretiva em $25 \%$ dos discursos. Deve ser considerado o fato de que juntamente à punição física muitas vezes são relatados gritos e ameaças.

Quando abusa muito, apanha (os filhos)... então apanha assim na perna, uma paulada, mas assim dos bons, pra não esquecer mesmo. Quando eu era pequeno, eu era terrível, apanhava muito. Naquele tempo podia surrar, né? E minha mãe não tinha dó, batia mesmo (P3).

Se não faz o que manda... meu marido uns empurrão ele já me deu, mas eu dou também nele uns empurrão. Meu pai era muito agressivo com minha mãe, batia muito nela também. Os filhos tem hora que a gente dá um empurrãozinho, uns tapinha vai se não obedece. Em nós, eu lembro quando era criança, quando não fazia coisa direito, tomava uma surra e pronto (P10). 
Às vezes falava as coisas, às vezes discutia. Ele (marido) quer falar mais alto, se estressar um pouco, ele fala bem alto. Tem muita briga na casa, violência psicológica... ele é especialista em violência mental, as palavras dele dói mais que qualquer tapa na cara. Diz que foi assim com ele quando era e pequeno e agora... com as crianças é assim também (P8).

\section{DISCUSSÃO}

As características socioeconômicas da amostra deste estudo são semelhantes ao perfil do usuário de crack no Brasil descrito no último levantamento nacional (FIOCRUZ \& ICICT, 2014) e estão alinhadas com a pesquisa de Bernardy e Oliveira (2012) com famílias de infratores usuários de drogas, na qual descrevem os participantes como sendo a maioria do sexo feminino, com idade entre 31 e 65 anos, com vários "casamentos", e baixa escolaridade. A presença maior de mulheres entre os familiares entrevistados foi anteriormente observada em outros estudos (Orth \& Moré, 2008; Bernardy \& Oliveira, 2012).

O fato de a mãe ser citada como a principal figura de referência de autoridade pode estar relacionado à tipologia familiar predominante no estudo, caracterizada pelo(s) recasamento(s) de um dos genitores ou ambos, uma vez que os filhos costumam permanecer com a mãe, que se responsabiliza por eles e os leva consigo nas demais uniões que realiza. A grande presença materna aliada a altos índices de ausência paterna no lar foi apontada, também, em outro estudo que aborda a estrutura familiar de usuários de crack (Narvaez et al., 2015).

A composição familiar mostra-se um aspecto relevante na compreensão do funcionamento das famílias. Esta pesquisa revela uma maioria de famílias reconstituídas (80\%), cujos genitores (ou ao menos um deles) realizaram de duas a cinco uniões. Genovese e Genovese (1997), estudando regras em famílias reconstituídas, relatam uma disciplina pouco clara e indefinida, o que relacionam às variações de regras e concessões a que estas vão sendo submetidas, conforme cada novo arranjo vai sendo realizado. Outros estudos associam separação parental com baixa coesão familiar e empobrecimento de comportamentos de controle dos filhos e de apoio dos pais (Wills \& Yaeger, 2003; Walker, Ainette, Wills, \& Mendonza, 2007).

Cumprir as regras estabelecidas por algum adulto envolve o conceito de reconhecimento de limites, respeito por aquele que as estabeleceu e obediência. Esta última é entendida como a resposta mais adequada da criança à instrução parental e só pode surgir quando há direcionamentos, ordens ou pedidos parentais que a antecedam (Wahler, 1997). São citadas como variáveis que a influenciam: clareza dos pedidos, valorização da resposta esperada, 
responsividade parental (Bueno, Santos, \& Moura, 2010), contexto familiar e estressores familiares (Bolsoni-Silva, Marturano, \& Manfrinato, 2005).

A obediência infantil às instruções dos pais é importante para instalar o desenvolvimento de repertórios de autonomia, autocontrole e socialização das crianças (Bueno et al., 2010; Wielevicki, Santos, \& Costelini, 2011). Estas necessitam de limites seguros, saudáveis e razoáveis, e entendem a orientação dos pais sobre o que devem ou não fazer como demonstração de cuidado e amor (Mondin, 2005).

O distanciamento afetivo entre pais e filhos, a disciplina severa e/ou inconsistente, a agressividade e a falta de atenção aos filhos causam efeitos muito prejudiciais para o indivíduo. A desatenção aos comportamentos apresentados pela criança, a ausência de regras claras e consequências consistentes, a punição aleatória, a negligência, a disciplina enfraquecida e o abuso físico são consideradas práticas educativas parentais negativas (Salvo, Silvares, \& Toni, 2005).

A permissividade dos pais, caracterizada como a falta de limites e de orientação do comportamento das crianças, priva-as de conhecer suas emoções e as possibilidades de resolução de seus problemas, prejudicando a aquisição da independência quando adultos e o desenvolvimento do sentimento de consideração pelo outro (Gottman \& Declaire, 1997).

Horta, Horta et al. (2014) revelam que o consumo de drogas está relacionado, entre outros fatores, ao descaso dos pais, descrevendo-o como inversamente associado aos cuidados e supervisão destes com os filhos. Segundo os autores, famílias com cuidados mais diretos com os filhos possuem uma capacidade protetora maior frente ao consumo de drogas. Silva et al. (2014) destacam o funcionamento familiar coeso e adaptado, e as regras e limites inerentes a este, como fatores de proteção ao consumo de drogas.

Famílias em que não há figura de autoridade, como aparecem neste estudo, nas quais todos ou ninguém determinam regras, fazem com que estas se tornem confusas, elásticas ou contraditórias, o que impossibilita à criança saber o que se espera dela e o discernimento entre o que deve ou não fazer.

Segundo Piaget (1932/1994), a criança nasce na anomia e, por meio das correções de seus pais, vai adquirindo a consciência de dever, reconhecendo nos mais velhos a fonte e o modelo das regras, chegando, assim, à heteronomia e obediência. Ao negligenciar seu papel disciplinador e mais tarde, para protegêlos, buscar remediar os problemas que os filhos causaram por desrespeito às regras e convenções sociais, os pais negam a estes as oportunidades de evolução moral. A autonomia - entendida como a capacidade de governar a si mesmo, fase na qual se adquirem as noções de livre-arbítrio, respeito mútuo, autorregulação, reciprocidade, cooperação, lei de causa e efeito - não se pode 
desenvolver numa atmosfera de autoridade, opressão moral e intelectual e tampouco na ausência de regras (Piaget, 1932/1994).

Quando às crianças e aos jovens não são oferecidas oportunidades de viver relações de respeito mútuo, reciprocidade, tomada de consciência, troca de pontos de vista e estabelecimento de relações de cooperação, há a tendência a se manterem heterônomos e assim permanecerem quando adultos (Piaget, 1932/1994). O desenvolvimento de uma razão autônoma torna o ser humano livre, com capacidade de julgamento e espírito crítico, sentido de experiência e coerência lógica, independente de toda autoridade exterior. Esta maturidade está relacionada a uma segurança emocional prévia, que possibilita à criança o desafio de provar que pode ser livre (Winnicott, 1958/2011).

Costa, Cenci e Spies (2014), em seu estudo sobre conjugalidade e parentalidade na dependência de crack, descrevem famílias com fragilidade de vínculos conjugais e parentais, problemas no estabelecimento de limites e no acompanhamento do desenvolvimento dos filhos. As autoras associam tais resultados às situações de subsistência que tiveram que ser administradas. Descrevem, também, a falta de apoio da rede primária - amigos e vizinhos - e secundária - escola e comunidade - como algo que contribui para a exposição aos riscos, fato que aumenta as chances de envolvimento com drogas. As privações e dificuldades enfrentadas por estas famílias constituem-se em estressores familiares que prejudicam as relações no grupo (Wahler, 1997; Mondin, 2005). Fatores como educação, desemprego e qualidade dos relacionamentos familiares também são citados por Faller et al. (2014).

As primeiras relações do indivíduo com o estabelecimento de ordens, deveres, responsabilidades e o reconhecimento destes na família parece se estender mais tarde na vida adulta no convívio em sociedade. Bucher-Maluschke (2007) revela a representação social de justiça em adolescentes infratores, no qual a palavra lei foi associada a palavras como obrigação, obediência, dever e importante, e definida por estes como uma ordem à qual se deve obedecer incondicionalmente com a finalidade de evitar o caos e manter as pessoas seguras. Enquanto Faller et al. (2014) apontam em seu estudo um grande número de usuários de crack que apresentam muitos problemas com a lei, Silva et al. (2014) revelam grande parte de encaminhamento judicial para atendimento no CAPS $A D$, observando que o envolvimento com a justiça muitas vezes precede o ingresso no Sistema de Saúde.

Sayago, Lucena-Santos, Horta e Oliveira (2014), estudando o perfil clínico e cognitivo de usuários de crack, descrevem grande prevalência de comportamentos de transgressão, dividindo estes achados em comportamentos de quebras de regras $(70,3 \%)$ e antissociais $(59,6 \%)$. Também apontam problemas no funcionamento adaptativo, relações interpessoais, com variação 
de $84,6 \%$ a $97,6 \%$, o que é um reflexo das habilidades sociais reduzidas nesta população.

Neste estudo observam-se muitos relatos de filhos educados, obedientes e que nunca deram trabalho. Estas também correspondem à descrição das mães participantes de outra pesquisa sobre usuários de crack (Orth \& Moré, 2008). Este dado chama a atenção pelo não raro envolvimento do usuário de droga, quando adulto, com questões de justiça, infração de leis e dificuldade de convívio social, como descrito acima. Quando criança terá sido ele um indivíduo com forte característica de cumprimento de regras familiares que não pôde transportar isto à vida adulta? Ou, diante do observado neste estudo, terá sido reconhecido como obediente devido à inconsistência e inexatidão das regras familiares a serem seguidas?

Estudos realizados com famílias de dependentes químicos apontam pais com dificuldade em estabelecer limites a seus filhos, e sugerem que isto pode resultar na falta de assertividade e na ambiguidade com relação a leis e normas manifestados pelos jovens (Wahler, 1997; Schenker \& Minayo, 2003; Costa et al., 2014).

A delegação das responsabilidades com relação aos filhos a outras pessoas e a fragilização dos vínculos conjugais e parentais cultiva um comportamento irresponsável, sem a construção de uma relação de confiança (Schenker \& Minayo, 2003; Costa et al., 2014). Isto pode ser devido a estressores familiares - como dificuldade econômica, desemprego, conflito conjugal, violência, divórcio e isolamento social - que criam condições para que os pais respondam apenas aos estímulos aversivos provenientes dos comportamentos de seus filhos. Tal conjunto de fatores pode tornar os pais mais sensíveis e atentos aos comportamentos inadequados, reagindo prontamente a eles, em detrimento de eventuais comportamentos adequados que passam despercebidos. Isto prejudica os padrões de interação dos pais com a criança, levando a condutas mal adaptadas de manejo familiar (Mondin, 2005; Bueno et al, 2010; Costa et al., 2014). Tais estressores são observados neste estudo, podendo prejudicar o manejo parental.

As práticas educativas parentais podem ser coercitivas - punição verbal ou física - e não coercitivas - por meio da negociação, explicação e comando verbal (Bueno et al., 2010). De acordo com estes autores, pesquisas relacionam problemas comportamentais, como agressão, desobediência e delinquência, a práticas educativas parentais coercitivas. As práticas não coercitivas favorecem a aprendizagem de comportamentos de obediência, ao contrário da punição, que não se mostra efetiva para a aprendizagem de comportamentos adequados.

No descumprimento de normas, observa-se neste estudo o uso de ameaça e desqualificação do outro, no qual está misturado, à intenção de educar, o descontrole emocional frente ao desagrado que a infração de regras trouxe. A 
punição física aparece como o principal modo de correção do comportamento. $\mathrm{Em}$ todos os relatos, aqueles que batem nos filhos ou parceiros contam que apanhavam de seus pais ou avós quando crianças. Ao que tudo indica, é esta a forma que aprenderam para lidar quando não se sentem obedecidos. Mais do que propriamente educar, expressam deste modo suas emoções diante do enfrentamento de sua autoridade. Programas visando o relacionamento familiar positivo como promoção à saúde e prevenção a riscos têm sido aplicados em outros países, mostrando-se efetivos (Orpinas et al., 2014).

A dinâmica familiar é um dos aspectos que merece ser considerado na compreensão do consumo do crack em meio a outros determinantes sociais mais complexos como a pobreza, o desemprego e a falta de perspectivas - problemas estes que atuam diretamente nas relações e qualidade das interações afetivas estabelecidas no grupo (Hart, 2013; Faller et al, 2014). Intervenções envolvendo o manejo familiar, visando a saúde de modo geral e o aumento de qualidade de vida podem trazer grandes contribuições na recuperação dos usuários de crack (Narvaez et al., 2015).

Embora não exista qualquer relação de causalidade entre cumprimento de normas e consumo de crack, a ausência da capacidade de reconhecer regras (por não tê-las vivenciado ou pela ausência de clareza destas) - e a consequente carência de regulação emocional - cumpre um papel importante no desenvolvimento do indivíduo. Isto, quando somado a fatores socioeconômicos, demográficos e culturais debilitantes, pode influenciar em excessos de qualquer natureza.

Este estudo possui uma limitação inerente à composição da amostra, uma vez que esta foi formada exclusivamente por famílias institucionalizadas, que, em maior ou menor grau, recebem cuidados e orientações da instituição que atende o membro usuário de crack, e, por esta razão, podem apresentar dinâmica familiar diferente daquelas sem nenhum acesso ao serviço de saúde. Outra limitação talvez seja o fato deste estudo não se ater ao gênero do usuário de crack, o que poderia revelar características diferentes na dinâmica de sua família.

Futuros estudos poderão apontar a existência de diferenças baseadas em gênero nas relações intrafamiliares desta população, como também se as percepções a respeito de sua unidade familiar são diferentes entre famílias de usuários que são institucionalizadas e aquelas que não o são. Estudos utilizando populações comparadas de famílias de usuários de crack e famílias que não possuam membros usuários também poderão ampliar a compreensão da influência das práticas parentais no desenvolvimento dos membros do grupo. Despertada a curiosidade sobre as razões que levam alguns membros da família a se tornem usuários de drogas e outros não, estudos considerando o ciclo familiar, as variações ambientais e socioculturais, assim como a resiliência 
individual, contribuiriam muito para a compreensão das motivações que levam o indivíduo ao consumo de crack e outras drogas.

\section{CONSIDERAÇÕES FINAIS}

Os limites estabelecidos no grupo familiar dos usuários de crack deste estudo revelam-se dúbios e indefinidos, o que pode causar nos membros incompreensão da resposta esperada a estes. Isto exerce influência no desenvolvimento da autonomia e na autorregulação das emoções destes.

A coerção como modo de educar os filhos ensina a estes uma filosofia de medo e dor, que muitas vezes os acompanha por toda a vida, levando-os a repetir este padrão de comportamento como forma de relacionamento aprendida e a perpetuar a violência de geração em geração.

O uso de punição e desqualificação observado quando se dá o descumprimento das normas pode estar relacionado a vínculos relacionais fragilizados, modelos aprendidos e estressores de causa externa à família que podem prejudicar o manejo parental.

A violência presente nas práticas educativas, assim como a contradição presente nas regras, cumpre uma função de comunicação, porém inadequada e pouco eficaz. Compreendida como modo de comunicação, esta seria passível de modificação e transformação. No entanto, faz-se necessária a intervenção de outros, alheios ao grupo, e que conhecem outras formas de expressão, uma vez que isto dificilmente se dará com naturalidade dentro do ambiente familiar que utiliza esse mesmo código há gerações, não percebendo que este não é efetivo.

Este estudo conduz à reflexão sobre a importância da inclusão do grupo familiar no tratamento da pessoa usuária de crack e destaca a relevância da utilização de estratégias terapêuticas focadas no fortalecimento de vínculos e recuperação de laços afetivos e sociais. A utilização de conceitos da Terapia Comunitária e da Terapia Familiar poderia auxiliar os profissionais na formação e acompanhamento de grupos de famílias abordando os conflitos vivenciados em função da droga e favorecendo a sensibilização quanto à expressão do carinho nas relações intrafamiliares, em busca de mudanças no modo de lidar com o problema.

Sugere-se a intervenção com ações educativas buscando diminuir as hostilidades, melhorar a comunicação entre os membros do grupo familiar, reduzir ganhos secundários e minimizar atitudes desqualificadoras e agressivas que, longe de cumprir o efeito de afastar o indivíduo da droga, reforçam o comportamento de consumo. Estas ações podem se dar por meio de confronto, semelhança e/ou identificação com outras famílias, no papel de coterapeutas, ou pela equipe de saúde por meio de sugestões e exposição de outros possíveis modos de atuação, visando propiciar a aprendizagem de novas formas de comportamento para lidar com conflitos. É importante que sejam abordadas as 
práticas parentais em uso, facilitando ao grupo reflexões e vivências que o possibilite romper com os moldes aprendidos e repetidos por gerações, auxiliando, assim, na modificação da dinâmica familiar, na promoção à saúde de outros membros e na recuperação dos pacientes.

\section{REFERÊNCIAS}

Bardin, L. (2011). Análise de Conteúdo (6a ed.). (L. A. Reto \& A. Pinheiro, Trads.). São Paulo, SP: Edições 70. (Trabalho original publicado em 1977).

Benchaya, M. C., Bisch, N. K., Moreira, T. C., Ferigolo, M., \& Barros, H. M. T. (2011). Pais não autoritativos e o impacto no uso de drogas: a percepção dos filhos adolescentes. Jornal de Pediatria, 87(3), 238-244. doi: 10.1590/S0021-75572011000300010

Bernardy, C. C. F., \& Oliveira, M. L. F. (2012). Uso de drogas por jovens infratores: perspectiva da família. Ciência, Cuidado e Saúde, 11(supl.), 168-175. doi: 10.4025/cienccuidsaude.v10i5.17072

Bolsoni-Silva, A. T., Marturano, E. M., \& Manfrinato, J. W. S. (2005). Mães avaliam comportamentos socialmente "desejados" e "indesejados" de préescolares. Psicologia em Estudo, 10(2), 245-252. doi: $10.1590 /$ S141373722005000200011

Bucher-Maluschke, J. S. N. F. (2007). Revisitando questões sobre lei, transgressão e família em suas interações com a psicologia, a psicanálise, o direito e a interdisciplinaridade possível. Psicologia: Teoria e Pesquisa, 23 (esp.), 89-96. doi: 10.1590/S0102-37722007000500017

Bueno, A. C. W, Santos, B. C., \& Moura, C. B. (2010). Obediência infantil: conceituação, medidas comportamentais e resultados de pesquisas. Psicologia: Teoria e Pesquisa, 26(2), 203-216. doi: 10.1590/S010237722010000200002

Claro, H. G., Oliveira, M. A. F., Ribeiro, A. P. R., Fernandes, C. C., Cruz, A. S., \& Santos, E. G. M. (2014). Perfil e padrão do uso de crack em crianças e adolescentes em situação de rua: uma revisão integrativa. SMAD Revista Eletrônica Saúde Mental, Álcool e Drogas, 10(1), 35-41. doi: 10.11606/issn.1806-6976.v10i1p-35-41

Costa, C. B., Cenci, C. M. B., \& Spies, D. W. (2014). Conjugalidade e parentalidade diante da dependência de crack de um filho. Contextos Clínicos, 7(2), 182-191. doi:10.4013/ctc.2014.72.06

Costa, L. F. (2010). A perspectiva sistêmica para a clínica da família. Psicologia: Teoria e Pesquisa, 26(esp.), 95-104. doi: 10.1590/S010237722010000500008

Faller, S., Peuker, A. C., Sordi, A., Stolf, A., Souza-Formigoni, M. L., Cruz, M. S., ... Kessler, F. (2014). Who seek public treatment for substance abuse in Brazil? Results of a multicenter study involving four Brazilian state capitals. 
Trends Psychiatry Psychotherapy, 36(4), 193-202. Recuperado de: http://www.scielo.br/pdf/trends/v36n4/2237-6089-trends-36-04-00193.pdf Fontanella, B. J. B., Ricas, J., \& Turato, E. R. (2008). Amostragem por saturação em pesquisas qualitativas e, saúde: contribuições teóricas. Cadernos de Saúde Pública, 24(1), 17-27. doi: 10.1590/S0102-311X2008000100003

Fundação Oswaldo Cruz, Instituto de Comunicação e Informação Científica e Tecnológica em Saúde. (2014). Pesquisa nacional sobre uso de crack: quem são os usuários de crack e/ou similares do Brasil? Quantos são nas capitais brasileiras? Rio de Janeiro, RJ: ICICT/ FIOCRUZ.

Genovese, Z. K., \& Genovese, T. A. (1997). Developing spousal relationship within stepfamilies. Families in Society, 78(3), 255-263. doi: 10.1606/1044-3894.773

Gottman, J. C., \& Declaire, J. (1997). Inteligência emocional e a arte de educar nossos filhos (A. C. Silva, Trad.). Rio de Janeiro, RJ: Objetiva.

Hart, C. (2013). High price: A neuroscientist's journey oneself-discovery that challenges everything you know about drugs and society. New York, NY: HarperCollins.

Horta, R. L., Horta, B. L., Costa, A. W. N., Prado, R. R., Oliveira-Campos, M., \& Malta, D. C. (2014). Uso na vida de substâncias ilícitas e fatores associados entre escolares brasileiros, Pesquisa Nacional de Saúde do Escolar (Pense 2012). Revista Brasileira de Epidemiologia, 17(1), 31-45. doi: 10.1590/1809-4503201400050004

Horta, R. L., Vieira, L. S., Balbinot, A. D., Oliveira, G. O., Poletto, S., \& Teixeira, V. A. (2014). Influencia da família no consumo de crack. Jornal Brasileiro de Psiquiatria, 63(2), 104-112. doi: 10.1590/0047-2085000000013

Laranjeira, R., Madruga, C. S., Ribeiro, M., Pinsky, I., Caetano, R., \& Mitsuhiro, S. S. (2012). II LENAD - Levantamento Nacional de Álcool e Drogas. São Paulo, SP: Instituto Nacional de Ciência e Tecnologia para Políticas Públicas do Álcool e Outras Drogas, Universidade Federal de São Paulo.

Lohr, S. S. (2001). Desenvolvimento das habilidades sociais como forma de prevenção. In H. J. Guilhardi, M. B. B. P. Madi, P. P. Queiroz, \& M. C. Scoz (Orgs.). Sobre comportamento e cognição: Expondo a variabilidade (Vol. 8, Cap. 23, pp. 190-194). São Paulo, SP: ESETEC.

Longman-Mills, S., Williams, Y. M. G., Rodriguez, M. O. M., Baquero, M. R. G., Rojas, J. D. G., Amaya, C. J., ... Tinoco, L. I. S. (2015). The association between adult drug abuse and childhood maltreatment in students attending seven universities in five countries in Latin America and one country in the Caribbean. Texto Contexto Enfermagem, 24(sp), 26-32. doi: 10.1590/0104-07072015001ESP026

Lubi, A. P. L (2003). Estilo parental e comportamento socialmente habilidoso da criança com pares. In M. Z. S. Brandão, V. M. Silva, \& S. M. Oliane (Orgs.). 
Sobre comportamento e cognição: A história e os avanços, a seleção por consequências em ação (Vol. 11, Cap. 46, pp. 536-541). São Paulo, SP: ESETEC.

Marques, A. C. P. R., \& Cruz, M. S. (2000). O adolescente e o uso de drogas. Revista Brasileira de Psiquiatria, 22(2), 32-36. doi: 10.1590/S151644462000000600009

Medeiros, K. T., Maciel, S. C., Souza, P. F., Tenório-Souza, F. M., \& Dias, C. C. V. (2013). Representações sociais do uso e abuso de drogas entre familiares de usuários. Psicologia em Estudo, 18(2), 269-279. doi: $10.1590 / S 1413-73722013000200008$

Mondin, E. M. C. (2005). Interações afetivas na família e na pré-escola. Estudos de Psicologia, 10(1), 131-138. Recuperado de http://www.scielo.br/pdf/epsic/v10n1/28016.pdf

Moreira, M. S. S. (2004). A dependência familiar. Revista da SPAGESP, 5(5), 8388. Recuperado de http://pepsic.bvsalud.org/scielo.php?script=sci_arttext\&pid=S167729702004000100015

Moreira, T. C., Figueiró, L. R., Fernandes, S., Justo, F. M., Dias, I. R., Barros, H. M. T., \& Ferigolo, M. (2013). Qualidade de vida em usuários de substâncias psicoativas, familiares e não usuários por meio do WHOQOL-BREF. Ciência \& Saúde Coletiva, 18(7), 1953-1962. doi:10.1590/S1413-81232013000700010

Moura, H. F., Benzano, D., Pechansky, F., \& Kessler, F. H. P. (2014). Crack/cocaine users show more Family problems then other substance use. Clinics, 69(7), 497-499. doi: 10.6061/clinics/2014(07)10

Narvaez, J. C. M., Pechansky, F., Jansen, K., Pinheiro, R. T., Silva, R. A., Kapczinski, F., \& Magalhães, P. V. (2015). Quality of life, social functioning, family structure, and treatment history associated with crack cocaine use in youth from the general population. Revista Brasileira de Psiquiatria, 37(3), 211-218. doi:10.1590/1516-4446-2014-1494

Orpinas, P., Ambrose, A., Maddaleno, M., Vulanovic, L., Mejia, M., Butrón, B., ... Soriano, I. (2014). Lessons learned in evaluating the Familias Fuertes program in three countries in Latin America. Revista Panamericana de Salud Pública, 36(6), 383-390. Recuperado de http://www.scielosp.org/scielo.php?script=sci_arttext\&pid=S102049892014001100005

Orth, A. P. S., \& Moré, C. L. O. O. (2008). Funcionamento de famílias com membros dependentes de substâncias psicoativas. Psicologia Argumento, 26(55), 293-303. Recuperado de http://www2.pucpr.br/reol/pb/index.php/pa?dd1=2525\&dd99=view\&dd98= $\mathrm{pb}$ 
Paula, M. L., Jorge, M. S. B., Albuquerque, R. A., \& Queiroz, L. M. (2014). Usuário de crack em situações de tratamento: experiências, significados e sentidos. Saúde e Sociedade, 23(1), 118-130. doi: 10.1590/S010412902014000100009

Paula, M. L., Jorge, M. S. B., Vasconcelos, M. G. F., \& Albuquerque, R. A. (2014). Assistência ao usuário de drogas na atenção primária à saúde. Psicologia em Estudo, 19(2), 223-233. doi: 10.1590/1413-737222025006

Paz, F. M., \& Colossi, P. M. (2013). Aspectos da dinâmica da família com dependência química. Estudos de Psicologia, 18(4), 551-558. Recuperado de http://www.scielo.br/pdf/epsic/v18n4/a02v18n4.pdf

Piaget, J. (1994). O juízo moral na criança (4a ed.). (E. Lenardon, Trad.). São Paulo, SP: Summus. (Trabalho original publicado em 1932).

Salvo, C. G., Silvares, E. F. M., \& Toni, P. M. (2005). Práticas educativas como forma de predição de problemas de comportamento e competência social. Estudos de Psicologia, 22(2), 187-195. doi: 10.1590/S0103166X2005000200008

Sayago, C. B. W., Lucena-Santos, P., Horta, R. L., \& Oliveira, M. L. (2014). Perfil Clínico e Cognitivo de usuários de crack internados. Psicologia: Reflexão e Crítica, 27(1), 21-28. doi: 10.1590/S0102-79722014000100003

Sayago, C. B., Lucena-Santos, P., Ribeiro, F., Yates, M. B., \& Oliveira, M., S. (2013). Fatores protetivos e de risco para o uso de crack e danos decorrentes de sua utilização: revisão de literatura. Aletheia, 42(3), 164174. Recuperado de:

http://pepsic.bvsalud.org/pdf/aletheia/n42/n42a14.pdf

Schenker, M., \& Minayo, M. C. S. (2003). A implicação da família no uso abusivo de drogas: uma revisão crítica. Ciência \& Saúde Coletiva, 8(1), 299-306. doi: $10.1590 /$ S1413-81232003000100022

Schenker, M., \& Minayo, M. C. S. (2005). Fatores de risco e de proteção para o uso de drogas na adolescência. Ciência \& Saúde Coletiva, 10(3), 707-17. doi: $10.1590 /$ S1413-81232005000300027

Seleghim, M. R., \& Oliveira, M. L. F. (2013). Influência do ambiente familiar no consumo de crack em usuários. Acta Paulista de Enfermagem, 26(3), 26368. doi: 10.1590/S0103-21002013000300010

Silva, C. C., Costa, M. C. O., Carvalho, R. C., Amaral, M. T. R., Cruz, N. L. A., \& Silva, M. R. (2014). Iniciação e consumo de substâncias psicoativas entre adolescentes e jovens de Centro de Atenção Psicossocial Antidrogas/CAPSAD. Ciência \& Saúde Coletiva, 19(3), 737-745. doi: 10.1590/141381232014193.15922013

Wahler, R. G. (1997). On the origins of children compliance and opposition: family context, reinforcement, and rules. Journal of Child and Family Studies, 6(2), 191-208. doi: 10.1023/A: 1025050724559 
Walker, C., Ainette, M. G., Wills, T. A., \& Mendonza, D. (2007). Religiosity and substance use: test of an indirect-effect model in early and middle adolescence. Psychology of Addictive Behaviors, 21(1), 84-96. doi: 10.1037/0893-164X.21.1.84

Wielewicki, A., Santos, B. C., \& Costelini, C. P. (2011). Variáveis e procedimentos de controle do comportamento de obedecer em crianças: uma análise da literatura. Temas em Psicologia, 19(2), 541-562. Recuperado de http://pepsic.bvsalud.org/scielo.php?script=sci_arttext\&pid=S1413389X2011000200016

Wills, T. A., \& Yaeger, A. M. (2003). Family factors and adolescents substance use: models and mechanisms. Current Directions in Psychological Science, 12(6), 222-6. doi: 10.1046/j.0963-7214.2003.01266.x

Winnicott, D. W. (2011). A família e o desenvolvimento individual (4a ed.). (M. B. Cipolla, Trad.). São Paulo, SP: Martins Fontes. (Trabalho original publicado em 1958).

Sobre os autores

Maria das Graças Rojas Soto é psicóloga pela Universidade de São Paulo e Mestre pelo Programa Saúde e Desenvolvimento na Região Centro-Oeste da Faculdade de Medicina da Universidade Federal do Mato Grosso do Sul. E-mail: gracyrojas@fiocruz.br

Verônica Fabíola Rozisca é psicóloga e mestre pela Universidade Federal do Mato Grosso do Sul. E-mail: verozisca@gmail.com

Rivaldo Venâncio da Cunha é graduado em medicina pela Universidade de Caxias do Sul e mestre e doutor em Medicina Tropical pela Fundação Oswaldo Cruz. Email: rivaldovc@fiocruz.br

Recebido em: 19/05/2016

Revisado em: 06/09/2016

Aceito em: 30/09/2016 